\title{
Investigation of elevated temperature effects on multiple layer piezoelectric ultrasonic transducers with adhesive bondlines by self-heating
}

\author{
Zhengbin $\mathrm{Wu}^{1,4}$, Sandy Cochran ${ }^{2}$ and $\mathrm{Bo} \mathrm{Wu}^{3}$ \\ 1Shenzhen Institutes of Advanced Technology, Chinese Academy of Sciences \\ ${ }^{3}$ Huazhong University of Science and Technology \\ 4The Chinese University of Hong Kong \\ China \\ 2University of Dundee \\ UK
}

\section{Introduction}

Ultrasound is referred to as sound signal with frequencies above the upper limit of human audible range, i.e. $20 \mathrm{kHz}$. The modern study and usage of ultrasound is believed to originate from the underwater detection of Paul Langevin in 1917 (Mason, 1976). Since then, ultrasound has taken an important role in a broad variety of applications including underwater sonar (Foote, 2008), non-destructive testing (NDT) and evaluation (Thompson, 1985), biomedical diagnosis and therapy (Duck, 1998), and process industry (Hoyle, 1994), and so on.

The generation of ultrasound waves for the first time by electromechanical transduction was based on the piezoelectric effect, which was discovered by Pierre and Jacques Curie in 1880 (Ballato, 1995). With the piezoelectric effect, mechanical energy and electrical energy can be converted into each other. As one of the most commonly used mechanisms, the piezoelectric effect has been intensively put into practical applications to produce ultrasound with piezoelectric transducers. Such transducers have a great flexibility of either piezoelectric materials or structural modes. In the 20th century, metal oxide-based piezoelectric ceramics (Jaffe et al., 1971) and other man-made materials including single crystals (Ritter et al., 2000), polymers (Fukada, 2000), composites (Akdogan et al., 2005) and thin films (Lakin, 2005) have enabled designers to employ the piezoelectric effect in increasingly wide applications based on their specific properties.

As one of the important structural types, multiple layer or stacked transducers have been widely used for their specific benefits (Cochran \& Hayward, 1999). In these multiple layer 
piezoelectric ultrasonic transducers, layers are connected mechanically in series and electrically in parallel, which can generate high strain through the establishment of high electric fields at relatively low operating voltages with their lower electrical impedance compared to single layer structure. Fig. 1 is the schematic diagram of an adhesively-bonded three-layer piezoelectric ultrasonic transducer.

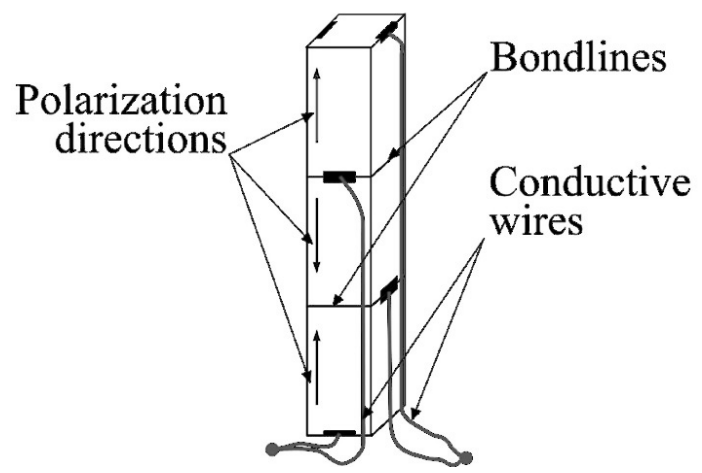

Fig. 1. Schematic diagram of a three-layer piezoelectric ultrasonic transducer

Fundamental work on multilayer structures has been carried out by several researchers (Sittig, 1967; Hossack \& Auld, 1993). The applications of multilayer structures have also been investigated in the area of medical ultrasound imaging. Multilayer piezoelectric ceramic structures for 2D array transducers were reported in 1994 (Goldberg \& Smith, 1994). It was found that the stacked structure has a better electrical impedance match and signal noise ratio (SNR) than the single layer. A multilayer PZT/polymer composite hybrid array was investigated in 1999 and it was concluded that the multilayer structure improved SNR and bandwidth (Mills \& Smith, 1999). Cofired resonators with the layer number, N, up to 20 was reported in 1996 (Greenstein \& Kumar, 1996). It was found the magnitude of the electrical impedance followed the relation $1 / \mathrm{N}$ of single layer, and the coupling coefficient $\mathrm{k}_{\mathrm{t}}$ remained relatively constant below 15 layers. Systematic studies of multilayer ultrasonic transducers with piezocomposites for low frequency applications have been carried out with investigating various prototypes and simulations (Cochran \& Hayward, 1999; Cochran et al., 1997; Cochran et al., 1998). In these work, the authors highlighted the advantages and the fabrication difficulties of the multilayer composite structures in specific low frequency applications, one of the difficulties being the bondlines. Multilayer ultrasonic transducers with non-uniform layer thicknesses have been studied with theoretical optimisation to improve their bandwidth (Abrar \& Cochran, 2007).

Excited by high electric field signals at their resonant frequencies, various losses in piezoelectric materials resulting in heat and temperature increase normally limit the practical applications of multilayer devices (Yao et al., 2000). In practical high power operation, the dominant type of transducers are mass-spring-mass models, i.e. Langevin/Tonpilz transducers. These structures are free of adhesive bondlines subjected to tensile stress because adhesive bonds have low thermal conductivity, low $Q_{m}$ value, and low 
maximum operating temperature. Different aspects such as loss effect, temperature rise, and self-heating mechanisms of piezoelectric devices have been studied on this topic, both on practical experiments (Robertson \& Cochran, 2002; Dubus et al., 2002; Wehrsdorfer et al., 1995; Zheng et al., 1996) and theoretical analyses (Wang et al., 1996; Flint et al., 1995; Ye \& Sun, 1997). Heat generation in various types of multilayer PZT-based actuators was reported in 1996 and a simplified analytic method to evaluate the temperature rise was also developed (Zheng et al., 1996). The phenomenology of mechanical, piezoelectric and dielectric losses was analyzed in 2001 (Uchino \& Hirose, 2001). It was also reported that how to measure these losses separately. A nonequilibrium thermodynamic model was developed in 2004, which couples irreversible mechanical, electric, and thermal processes, all contributing to dissipation (Xia \& Hanagud, 2004). It was verified that the dissipation nonlinearly depends on operating frequency, related to characteristic relaxation of irreversible processes. Generally, however, it is still difficult to accurately simulate the thermal property of multilayer piezoelectric devices for their complicated structural and material behaviors under dynamic excitation conditions. Experimental investigations into the dynamic and thermal properties of several Langevin/Tonpilz structures have been conducted from different aspects (Ochi et al., 1985; Yao et al., 2000; Zheng et al., 1996; Dubus et al., 2002; Pritchard et al., 2004). For such typical multilayer piezoelectric devices, the frequency bandwidth under high level dynamic conditions is seriously limited. This disadvantage of traditional structures may be overcome to use a multilayer piezoelectric composite structure. But it has been found that this is infeasible for its practical manufacture procedure issues (Robertson \& Cochran, 2002).

To solve this problem, therefore, adhesively-bonded multilayer ultrasonic transducers have been suggested to be used for high power applications at relatively low frequencies. It is desired to investigate the thermal and mechanical behaviors of bondlines with newly developed adhesives in multilayer transducers under dynamic drive and self-heating conditions.

In this chapter, the behaviour of multilayer piezoelectric ultrasonic transducers with two typical adhesive bondlines under self-heating conditions is to be studied. The material characteristics of high Curie temperature piezoelectric cermaic, which was used to manufacture the multilayer structures, under different temperatures will be investigated. The effects of self-heating on temperature rise and mechanical output characteristics of adhesively-bonded multilayer ultrasonic transducers under various dynamic drive conditions are to be reported. Further investigation is also to be presented into the loss characteristics derived from measured time-temperature behaviour of multilayer piezoelectric ultrasonic transducers with adhesive bondlines, corresponding to stable temperature rises. In particular, the effect of the resultant higher temperature on the complete structures including the piezoelectric material and the adhesive bondlines will be considered. Various drive electric fields and the corresponding temperatures at resonant frequency will be reported too. 


\section{Material and Experimental Characterizations}

Ultrasonic transducers and other smart devices made from piezoelectric materials operated under self-heating or elevated temperature desire high Curie temperature piezoelectric materials. Lead metaniobate piezoelectric ceramic (PZ35, Ferroperm Piezoceramics A/S, Hejreskovvej 18A, DK-3490 Kvistgård, Denmark) has a higher Curie temperature around $500{ }^{\circ} \mathrm{C}$ and therefore is approriate to elevated temperature applications. It also has very low width vibration mode. Its high loss properties compared to lead zirconate titanate (PZT) piezoceramic allow it to be manufactured into broadband ultrasonic transducers.

Two two-part epoxy adhesives were selected to bond multilayer structures here, RX771/HY1300 and silver-loaded epoxy. RX771/HY1300 (Robnor Resins Ltd, Swindon, UK) has commonly been used as the polymer in piezocomposite materials. It has low viscosity of 0.6-1.2 $\mathrm{Pa} \mathrm{s}$ at $25^{\circ} \mathrm{C}$ prior to curing and is able to produce bondlines with thickness in the range of several microns (Wu el al., 2005). Silver-loaded epoxy (Part No. 186-3616, RS Components Ltd, Corby, UK) is a highly viscous gray paste before curing, and often used to establish electrical contacts in electronic devices. The glass transition temperature $\mathrm{T}_{\mathrm{g}}$ of RX771/HY1300 is $60{ }^{\circ} \mathrm{C}$ after cured while silver-loaded epoxy has a maximum useful temperature of $150{ }^{\circ} \mathrm{C}$ after set, which offers a potential to overcome the disbond issue of multilayer structures resulted from the weak thermal characteristics of epoxy adhesive bondlines under elevated temperature.

The electrical impedance characteristics of the piezoelectric ultrasonic transducers were measured by Impedance Analyzer HP4192A (Agilent, Winnersh Triangle, Wokingham, Berkshire, UK). The surface displacement of the transducers was measured with a laser vibrometer system (Laser Vibrometer Controller OFV-2700-2 and Differential Fiber Optic Unit OFV-512, Polytec GmbH, Waldbronn, Germany).

\section{Effects of Elevated Temperature on Piezoelectric Material Parameters}

In oder to predict the effects of self-heating or elevated temperature on the multilayer piezoelectric transducers made from it, it is fundamentally crucial to consider its material constant variations with increased temperature beforehand.

For the characterization of piezoelectric materials, the standard method is normally used to analyze the electrical impedance resonant characteristics (ANSI/IEEE, 1987). The Piezoelectric Resonance Analysis Program (PRAP, TASI Technical Software Inc., Kingston, Ontario, Canada) offers a quick convergent fitting and analysis process and a more accurate characterization of lossy piezoelectric materials such as lead metaniobate or piezoelectric polymers (Kwok et al., 1997). Elevated temperature may enhance the loss mechanisms of piezoelectric materials (Sherrit et al., 1999). Here the behaviour of lead metaniobate piezoelectric ceramic from ambient temperature to higher temperatures was investigated. Material parameters were precisely calculated by theoretical fitting and analysis with PRAP.

A lead metaniobate disc under thickness extensional vibration mode was studied here. The diameter and thickness are $12 \mathrm{~mm}$ and $0.7 \mathrm{~mm}$ respectively. When the measurements going 
on, the lead metaniobate sample was put inside a temperature-controllable oven and connected outside with the HP4192A Impedance Analyzer through a short braided coax cable, which has $50 \mathrm{Ohm}$ impedance and low attenuation over the studied frequency domain. A digital thermocouple meter was used to record the inside temperature of the oven. The electrical impedance resonant characteristics of the lead metaniobate sample were measured at $25^{\circ} \mathrm{C}, 40^{\circ} \mathrm{C}, 60^{\circ} \mathrm{C}, 80^{\circ} \mathrm{C}$, and $100^{\circ} \mathrm{C}$, respectively.

The basic theoretical model of the PRAP analysis package was developed (Smits, 1976; Sherrit et al., 1992). The initial value of the elastic stiffness constant under constant displacement $C_{33}{ }^{2 *}$ is calculated from Equations (1) and (2).

$$
\begin{gathered}
f_{p}^{*}=f_{p}(1-i w)^{-1 / 2} \\
C_{33}^{D^{*}}=4 \rho t^{2} f_{p}^{* 2}
\end{gathered}
$$

Here $f_{p}$ is the frequency where the real part of $f Z(f)$ has a maximum, $\rho$ and $t$ are the density and thickness of the sample respectively, $w$ is the ratio of the frequency difference between where the imaginary part of $f Z(f)$ has the minimum and the maximum to $f_{p}$, and * represents complex variants.

The imaginary part of all the material parameters represents the respective loss. Two arbitrary points at frequencies either side of $f_{p}$ along with the initial value for the elastic constant $C_{33^{2}}{ }^{*}$ are used to calculate the electromechanical coupling constant $K_{t}^{*}$ and the permittivity under constant strain $\varepsilon_{33}{ }^{5 *}$ of the sample following Equation (3)

$$
Z(f)^{*}=\frac{t}{i 2 \pi f \varepsilon_{33}^{S^{*}} A}\left[1-\frac{K_{t}^{* 2} \tan \left(\pi f t \sqrt{\rho / C_{33}^{D^{*}}}\right)}{\pi f t \sqrt{\rho / C_{33}^{D^{*}}}}\right]
$$

where, $f$ and $A$ are frequency and the sample electrode area respectively. The obtained values $K_{t}{ }^{*}, \varepsilon_{33}{ }^{* *}$ and $f_{p}{ }^{*}$ can be used to calculated a new $C_{33}{ }^{* *}$ following the relationship of Equation (3). The process continues iteratively until the calculated results becoming convergent. The complex piezoelectric constant $\mathrm{e}_{33}{ }^{*}$ can be calculated from Equation (4).

$$
e_{33}^{*}=\sqrt{K_{t}^{* 2} C_{33}^{D^{*}} \varepsilon_{33}^{S^{*}}}
$$

PRAP was used to fit and analyze the measured electrical impedance resonant characteristics. The magnitude and phase of the measured data and fitted results at $25^{\circ} \mathrm{C}, 60$ ${ }^{\circ} \mathrm{C}$, and $100{ }^{\circ} \mathrm{C}$ are shown in Fig. 2. From Fig. 2, it is found that there is a good agreement between the fitted results and measured data. 

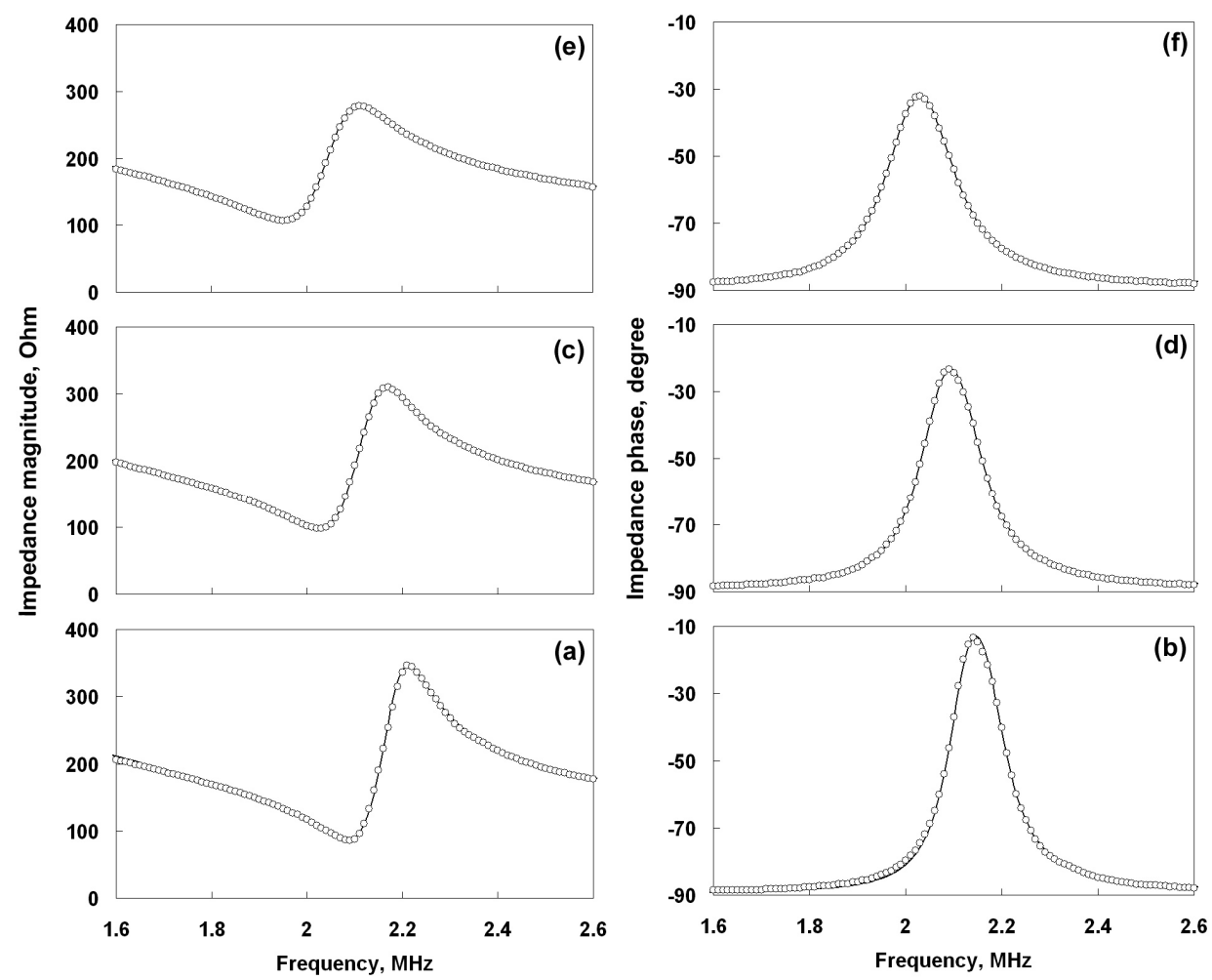

Fig. 2. Magnitude (a, c, and e) and phase (b, d, and f) impedance resonant characteristics of lead metaniobate at $25^{\circ} \mathrm{C}$ (a and b), $60{ }^{\circ} \mathrm{C}$ (c and d), and $100{ }^{\circ} \mathrm{C}$ (e and f) (circle represents measured value, and solid line calculated data.)

\begin{tabular}{|l|l|l|l|l|l|}
\hline Temperature & $25^{\circ} \mathrm{C}$ & $40^{\circ} \mathrm{C}$ & $60{ }^{\circ} \mathrm{C}$ & $80{ }^{\circ} \mathrm{C}$ & $100{ }^{\circ} \mathrm{C}$ \\
\hline$f_{p}, \mathrm{MHz}$ & 2.19 & 2.16 & 2.13 & 2.10 & 2.07 \\
\hline $\mathrm{Imag}(f)$ & 0.0543 & 0.0585 & 0.0643 & 0.0708 & 0.0766 \\
\hline $\mathrm{C}_{33}, 10^{10} \mathrm{~N} / \mathrm{m}^{2}$ & 5.00 & 4.89 & 4.77 & 4.61 & 4.48 \\
\hline $\operatorname{Imag}(\mathrm{C})$ & 0.248 & 0.266 & 0.288 & 0.311 & 0.332 \\
\hline$K_{t}$ & 0.296 & 0.297 & 0.300 & 0.302 & 0.304 \\
\hline $\operatorname{Imag}(\mathrm{K})$ & 0.00678 & 0.00416 & 0.00216 & 0.00160 & 0.00188 \\
\hline$\varepsilon^{S_{33}, 10^{-9} \mathrm{~F} / \mathrm{m}}$ & 2.40 & 2.44 & 2.50 & 2.56 & 2.62 \\
\hline $\operatorname{Imag}(\varepsilon)$ & -0.0326 & -0.0505 & -0.0400 & -0.0504 & -0.0548 \\
\hline$e_{33}, \mathrm{C} / \mathrm{m}^{2}$ & 3.248 & 3.247 & 3.278 & 3.283 & 3.298 \\
\hline $\operatorname{Imag}(\mathrm{e})$ & 0.133 & 0.100 & 0.096 & 0.095 & 0.108 \\
\hline
\end{tabular}

Table 1. Some material parameters of lead metaniobate at various temperatures

Table 1 shows the analyzed material property data at $25^{\circ} \mathrm{C}, 40^{\circ} \mathrm{C}, 60^{\circ} \mathrm{C}, 80^{\circ} \mathrm{C}$, and $100{ }^{\circ} \mathrm{C}$, respectively. The loss component of each parameter is represented by the imaginary part value. Increasing the temperature from $25{ }^{\circ} \mathrm{C}$ to $100{ }^{\circ} \mathrm{C}$ alters $f_{p}$ by more than $5 \%$ from 2.19 
$\mathrm{MHz}$ to $2.07 \mathrm{MHz}$. Furthermore, Imag(f), which reflects the elastic damping characteristic, becomes greater with the higher temperatures. These are also reflected by the data in Fig. 2 . Because the thermal expansion effect of piezoelectric ceramics in the temperature range studied here is negligible (Takahashi et al., 1974), the shift of $f_{p}$ is attributed to the thermal variation of sound velocity of lead metaniobate. This hypothesis is supported by the $10 \%$ reduction of $C_{33} D$ over the same temperature range. The sound velocity of lead metaniobate is a function of the elastic stiffness coefficient and density. Whilst the density was found to be temperature invariant, it can be seen from Table 1 that $C_{33} D$ has a value of $5.00 \times 10^{10} \mathrm{~N} / \mathrm{m}^{2}$ at $25^{\circ} \mathrm{C}$ but only $4.48 \times 10^{10} \mathrm{~N} / \mathrm{m}^{2}$ at $100{ }^{\circ} \mathrm{C}$. Increased temperature also caused increasing Imag(C). The sound velocity and the elastic damping changes are thought to result from the characteristic variation of the sound wave propagation in the material at various temperatures. The analyzed elastic constants of lead metaniobate presented here have a different trend from those reported data of PZT ceramics (Sherrit et al., 1999), wherein the elastic compliance coefficients shifted downwards under higher temperatures. However the dielectric behaviour follows similar trends to that reported for PZT (Sherrit et al., 1999) and the authors observed that $\varepsilon_{33} S$ increases by $7 \%$ from $2.40 \times 10^{-9} \mathrm{~F} / \mathrm{m}$ to $2.62 \times 10^{-9} \mathrm{~F} / \mathrm{m}$ as temperature increases from $25{ }^{\circ} \mathrm{C}$ to $100{ }^{\circ} \mathrm{C}$. $K_{t}$ and $\mathrm{e}_{33}$ have changes less than $3 \%$ with the elevating temperature.

\section{Self-heating Effects}

Now that the stable elevated temperature effects on the piezoelectric material properties have been studied, in this section, the effects of self-heating and resulted stable temperature rise on multilayer piezoelectric transducers with adhesive bondlines are to be investigated. Two two-layer lead metaniobate transducers bonded with RX771/HY1300 and silver-loaded epoxy respectively were prepared. Each active layer of two-layer thickness extensional mode transducers has a lateral dimension of $20 \mathrm{~mm}$ square and thickness of $1.55 \mathrm{~mm}$. After fabrication, the bondlines of RX771/HY1300 and silver-loaded epoxy have mean thicknesses of $10.4 \mu \mathrm{m}$ and $104 \mu \mathrm{m}$ respectively, which were determined by an acoustical fitting process (Wu et al., 2003). A single-layer lead metaniobate transducer with the same lateral dimensions as the two layer transducers and the thickness of $1.49 \mathrm{~mm}$ was also prepared and tested. The thickness extensional vibration mode single layer transducer was used to compare to the multilayer structures, which is able to be used to justify various loss effects from the piezoelectric material and adhesive bondlines on the multilayer transducers.

A thermocouple was mounted near the centre of one major working surface of those samples, as shown in Fig. 3, to measure its surface temperature, which connected to a digital meter $\left(0.1{ }^{\circ} \mathrm{C}\right.$ resolution). The effect of this thermocouple on the transducer is considered to have been very minor and is neglected here. In each experiment, a stable temperature value was recorded two minutes after the electrical signal was applied. 


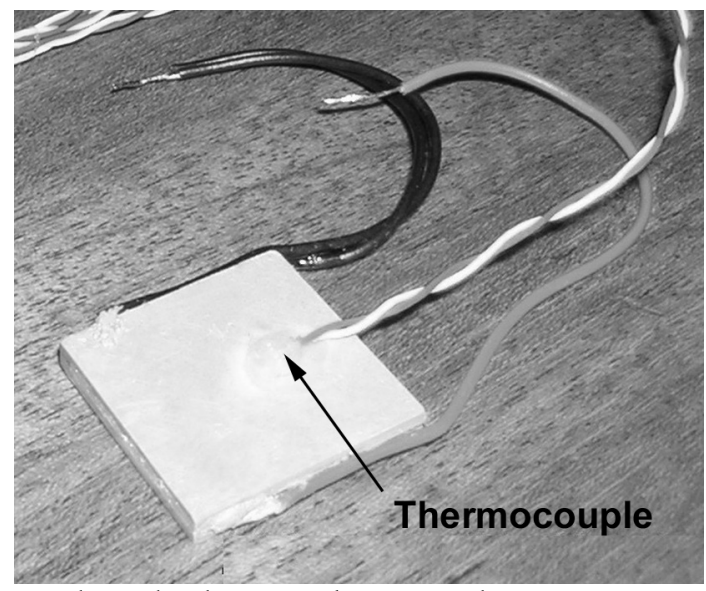

Fig. 3. Prototype of a two-layer lead metaniobate transducer

The surface displacement frequency response of the two multilayer transducers at ambient temperature was measured. The normalized surface displacement responses in frequency domain were obtained by the absolute displacement values dividing the maximum, $233 \mathrm{~nm}$, of the two transducers under 50-cycle tone burst sinusoidal driving signal at fixed $200 \mathrm{~V}$ peak-peak level without self-heating, which are shown in Fig. 4. The thickness extension within the frequency domain between 400 and $500 \mathrm{kHz}$ is the dominant vibration mode for the both transducers, while the much lower peaks around $330 \mathrm{kHz}$ represent the widthvibrational modes. Those around $1.45 \mathrm{MHz}$ are the third harmonies of the thickness extension vibration mode of the multilayer transducers. Therefore the latter two vibration modes in the frequency range up to $1.8 \mathrm{MHz}$ can simply be ignored. The multilayer transducer with silver-loaded epoxy bondline has the lower thickness extensional vibration mode resonant frequency, $419 \mathrm{kHz}$, than the one with RX771/HY1300, $496 \mathrm{kHz}$ for their different bondlines and longitudinal ultrasound signal propagation time along the thickness direction.

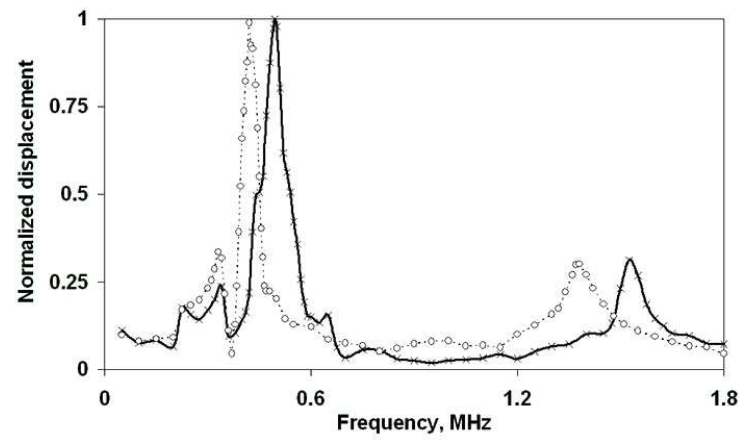

Fig. 4. Surface displacement frequency spectrum of the two-layer lead metaniobate transducers bonded with RX771/HY1300 (solid line and cross) and silver-loaded epoxy (dashed line and circle), respectively 
For a working ultrasonic transducer, the total electrical power supplied by the driver $P_{T}$ can be calculated as equation (5).

$$
P_{T}=\frac{\left(E \cdot t_{E}\right)^{2}}{R_{E}} \cdot \eta
$$

Here $E$ is root of mean square (RMS) value of applied electric field, $t_{E}$ is the transducer thickness under applied electric field, $\eta$ is the driving duty cycle, and $R_{E}$ the transducer's electrical resistance.

For the transducers studied here, operating in air, the radiated acoustic power is approximately zero because of the mismatch of acoustic impedance. Therefore $P_{T}$ is equal to the sum of the power losses, which comprise mechanical power loss, $P_{M}$, and dielectric power loss, $P_{D}$, resulting in heating and temperature rises. The power losses are a function of the stable temperature rise in Kelvin of the piezoelectric transducers under constant (zero) stress condition, $\delta T$, and the effective heat transfer constant, $k_{H}$. Their relationships are shown as equation (6).

$$
P_{T}=P_{M}+P_{D}=k_{H} \cdot \delta T
$$

Here, $\delta T=T-T_{A} . T$ is the equilibrium temperature at the surface of the transducer, $T_{A}$ the ambient temperature. At resonance the power dissipation of a transducer is thought to be primarily due to the mechanical loss (Sherrit, 2001). Under free load conditions, the relationships between $P_{M}$, the mechanical loss resistance $R_{M}$, the RMS displacement of the working surface, $d$, the driving frequency, $f$, and $\eta$ is described as equation (7).

$$
P_{M}=R_{M} \cdot(2 \pi f \cdot d)^{2} \cdot \eta
$$

All the transducers reported in this chapter were tested in air by tone burst sinusoidal signals with different duty cycles. The drive frequencies of all the transducers were their measured resonant frequencies under longitudinal thickness extensional vibration mode without self-heating. The detailed excitation conditions are listed in Table 2.

\begin{tabular}{|l|l|l|l|l|l|}
\hline & $\begin{array}{l}\text { Frequency } \\
(\mathrm{kHz})\end{array}$ & \multicolumn{2}{|l|}{$\begin{array}{l}\text { Lower duty } \\
\text { cycle }\end{array}$} & \multicolumn{2}{l|}{$\begin{array}{l}\text { Higher duty } \\
\text { cycle }\end{array}$} \\
\cline { 3 - 6 } & & $\begin{array}{l}\text { Cycle } \\
\text { number }\end{array}$ & $\begin{array}{l}\text { Duty } \\
\text { cycle }\end{array}$ & $\begin{array}{l}\text { Cycle } \\
\text { number }\end{array}$ & $\begin{array}{l}\text { Duty } \\
\text { cycle }\end{array}$ \\
\hline $\begin{array}{l}\text { Two-layer transducer } \\
\text { with RX771/HY1300 }\end{array}$ & 496 & 50 & $1.0 \%$ & 1000 & $20 \%$ \\
\hline $\begin{array}{l}\text { Two-layer transducer } \\
\text { with silver-loaded } \\
\text { epoxy }\end{array}$ & 419 & 50 & $1.2 \%$ & 1000 & $24 \%$ \\
\hline Single-layer transducer & 1021 & 100 & $1.0 \%$ & 2000 & $20 \%$ \\
\hline
\end{tabular}

Table 2. Excitation conditions for the lead metaniobate transducers 
Excited by low duty cycles at resonance, the measured temperature and resonant frequency of all the transducers remain almost unchanged due to the low power and limited amplitude electric field. As shown in Fig. 5, under no more than $1.2 \%$ duty cycle excitation, the resonant displacement of all the transducers has a nearly linear relationship with the driving electric field within the range up to around $160 \mathrm{~V} \mathrm{~mm}^{-1}$. According to the relationships shown in equations (5) and (7), this indicates that the mechanical power loss is approximately proportional to the low amplitude driving power. It is also found that the displacement responses of the two layer transducers are approximately twice that of the single layer at a given electric field level indicating that under low power and ambient temperature conditions, the adhesive bondlines support the resonant vibration of multilayer structures very well.

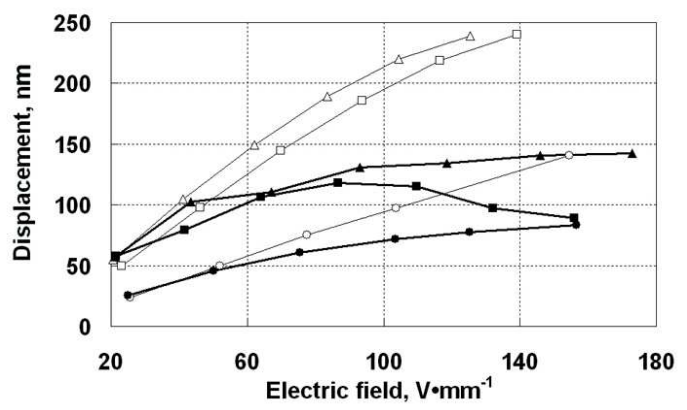

Fig. 5. Measured displacement amplitude under various driving electric fields of the transducers (solid marks and thick lines, high duty cycle; hollow marks and thin lines, low duty cycle; circle, single layer transducer; triangle, two-layer transducer bonded with RX771/HY1300; square, two-layer transducer bonded with silver-loaded epoxy)

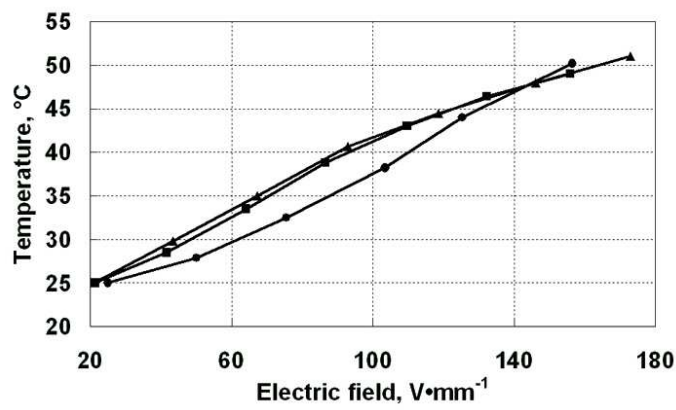

Fig. 6. Measured temperature characteristics under various driving electric fields of the transducers (solid marks and thick lines, high duty cycle; hollow marks and thin lines, low duty cycle; circle, single layer transducer; triangle, two-layer transducer bonded with RX771/HY1300; square, two-layer transducer bonded with silver-loaded epoxy)

With the duty cycle increased to above $20 \%$, as shown in Fig. 6, the temperature of the transducers rises from ambient to around $50{ }^{\circ} \mathrm{C}$ with electric field increasing from below 30 
$\mathrm{V} \cdot \mathrm{mm}^{-1}$ to above $150 \mathrm{~V} \mathrm{~mm}-1$. According to equation (6), the elevated temperature is resulted from the higher excitation and power losses. For the single layer ceramic sample, as shown in Fig. 5, the displacement response presents a decreased gradient with the high duty cycle excitation electric field increasing from approximately $50 \mathrm{~V} \mathrm{~mm}-1$ to $155 \mathrm{~V} \mathrm{~mm}^{-1}$, indicating that, at a given electric field, the displacement at high duty cycle is lower than at low duty cycle excitation. This is attributed to the variation of electrical impedance frequency characteristics of this ceramic with the elevated temperature resulting from high duty cycle driving as presented in the previous section. The peak displacement of the twolayer transducer with silver-loaded epoxy under high duty cycle excitation corresponds to an electric field of $86.5 \mathrm{~V} \mathrm{~mm}^{-1}$. Above this value, the displacement decreases with the increased electric field and resulting in higher temperature above $38.8{ }^{\circ} \mathrm{C}$, which is due to the reduced elastic coefficient of the bondline. For the two layer transducer with RX771/HY1300, although its surface displacement increases with increasing electric field in the whole range covered in the present investigation, the value is reduced and is less than twice that of the single layer transducer under high duty cycle drive conditions. This is attributed to the lower elastic coefficient of RX771/HY1300 with increasing temperature, below its $\mathrm{T}_{\mathrm{g}}$, and higher excitation amplitudes and power losses (Wu \& Cochran, 2008).

\section{Loss Characteristics of Self-heating}

In the previous section, the self-heating effects on the performance of multilayer piezoelectric ultrasonic transducers with adhesive bondlines have been investigated. In this section, further study is to be carried out to analyze the loss characteristics of self-heating.

The time-temperature characteristics of the single and two layer transducers, which have been introduced in the previous section, at resonances under different drive electric fields were measured and shown in Fig. 7. As shown in Fig. 7, the temperature rise of all transducers became stable less than five minutes after excitations applied. The stable temperature rise increases with the enhanced electric fields for all the piezoelectric ultrasonic transducers. The time-temperature behaviour of a piezoelectric device can be described by Equation (8) (Zheng et al., 1996)

$$
\Delta T\left(t_{s}\right)=\delta T\left(1-e^{-t_{s} / \alpha}\right)
$$

where $\Delta T\left(t_{s}\right)$ is the temperature rise of the piezoelectric device at the instantaneous time $t_{s,}$ and $\alpha$ the time constant. Using Equation (8), the theoretical exponential time-temperature characteristics of all the transducers under different electric fields were calculated with measured $\delta T$ and fitted $\alpha$ and shown in Fig. 7. Generally, the experimental results agree the theoretical data well but it is also found that the measured results rise steeper than theory at the beginning of the experiments. This indicates that more than one time constants are involved in the self-heating processes. Further accurate characterization of the whole selfheating process is proposed to be studied in the future work. 
The stable temperature rise $\delta T$, which is the function of loss, can be approximately expressed as equation (9) (Zheng et al., 1996).

$$
\delta T=\frac{u f \eta v_{e}}{k(T) A_{t}}
$$

Here $u$ the total loss of the actuator per unit volume and driving cycle, and $v_{e}$ the active volume of the actuator. $A_{t}$ and $k(T)$ are the total surface area of the device and the overall heat transfer coefficient respectively.

The time constant $\alpha$ in Equation (8) is defined as

$$
\alpha=\frac{v \rho c}{k(T) A_{t}}
$$

where $v$ is the total volume of the device. $c$ is the specific heat capacity of the actuator. In the present work, because the volume of the relatively thin bondlines was negligible compared to the piezoelectric material and no other material was present, $v_{e}=v$ then the function below is built up by dividing Equation (9) to Equation (10)

$$
\frac{\delta T}{\alpha}=\frac{f \eta}{\rho} \cdot \beta
$$

where the loss constant $\beta=u / c$. Since $c$ is a constant for each specific material, $\beta$ is proportional to $u$ and is used to characterize the loss of drive signal in the piezoelectric devices, here relating only to the relevant piezoceramic used in this work. Using Equation (11), with measured $\delta T$, fitted $\alpha$, density of lead metaniobate $\rho$, and driving signal frequency $f$, and duty cycle $\eta$, the loss constant $\beta$ of the piezoelectric ultrasonic transducers is calculated to characterize their loss. The temperature and the normalized loss constant for each transducer versus surface displacement are shown in Fig 8. The normalized loss constant is calculated by loss constant $\beta$ over the maximum of all the transducers under different drives. It is found that the normalized loss constant corresponds well with the temperature for all transducers as shown in Fig.8. 


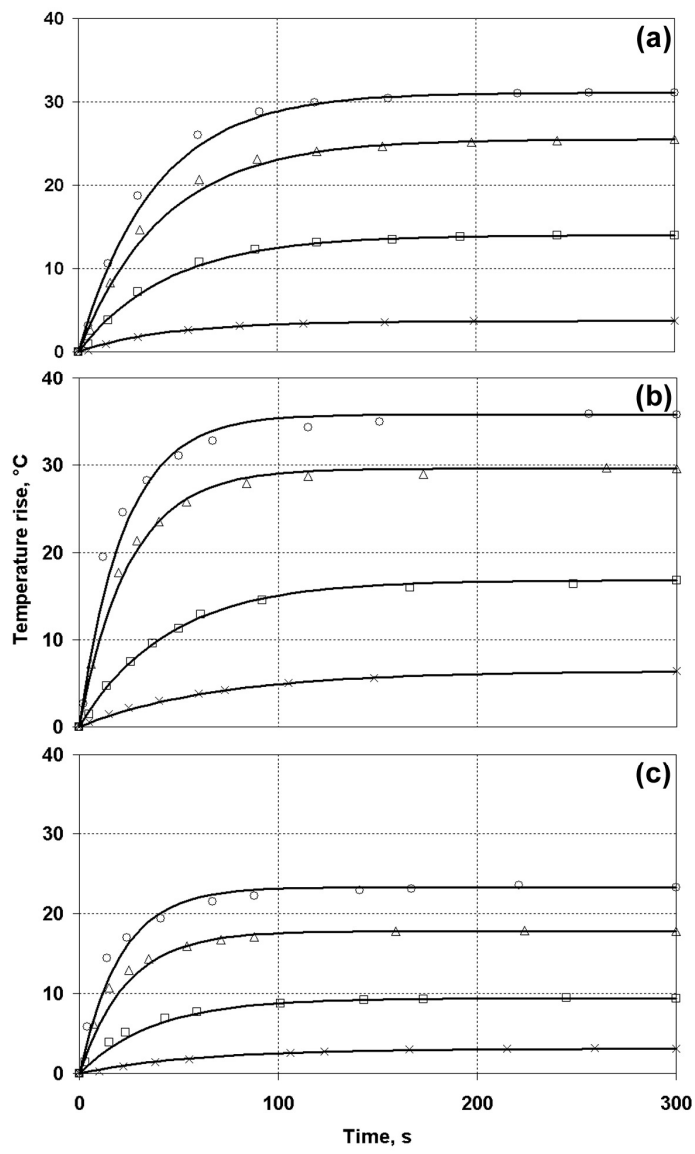

Fig. 7. Comparison of time-temperature characteristics of the single-layer (a) and two-layer transducers bonded with RX771/HY1300 (b) and with silver-loaded epoxy (c). Experimental results under various electric fields are shown (markers) along with theoretically fitted data (solid lines). [(a) cross, $50.1 \mathrm{~V} \mathrm{~mm}^{-1}$; rectangle, $103.4 \mathrm{~V} \mathrm{~mm}^{-1}$; triangle, $156.4 \mathrm{~V} \mathrm{~mm}^{-1}$; and circle, 183.2 $\mathrm{V} \mathrm{mm}{ }^{-1}$; (b) cross, $43.2 \mathrm{~V} \mathrm{~mm}^{-1}$; rectangle, $92.4 \mathrm{~V} \mathrm{~mm} \mathrm{~mm}^{-1}$; triangle, $191.8 \mathrm{~V} \mathrm{~mm}^{-1}$; and circle, $233.9 \mathrm{~V} \mathrm{~mm}^{-1}$; (c) cross, $45.7 \mathrm{~V} \mathrm{~mm}^{-1}$; rectangle, $97.0 \mathrm{~V} \mathrm{~mm} \mathrm{~mm}^{-1}$; triangle, 198.0 $\mathrm{V} \cdot \mathrm{mm}^{-1}$; and circle, $249.2 \mathrm{~V} \cdot \mathrm{mm}^{-1}$ ] 


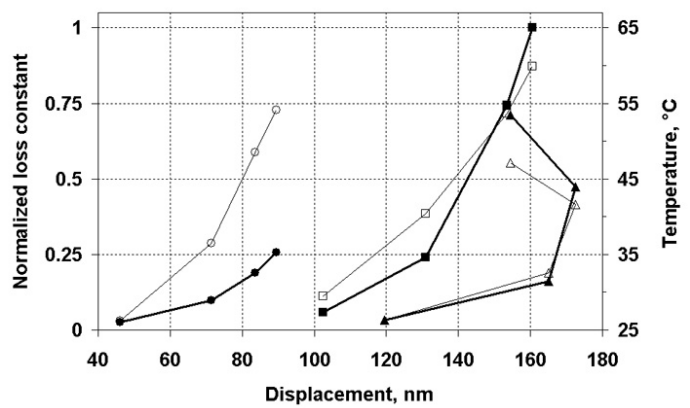

Fig. 8. The normalized loss constant (solid markers and solid lines) and the temperature (hollow markers and thin lines) of the sing-layer and two-layer transducers versus measured displacement. (circle, single-layer transducer; square, two-layer transducer with RX771/HY1300; triangle, two-layer transducer with a silver-loaded epoxy)

Under resonant drive conditions, the total loss is primarily due to the mechanical losses, although the ferroelectric hysteresis loss may become dominant under off-resonance drive conditions (Uchino \& Hirose, 2001). For the single-layer transducer and the transducer bonded with RX771/HY1300, the normalized loss constant and the temperature are increased with the enhanced surface displacement in the temperature range below $60^{\circ} \mathrm{C}$, i.e. $\mathrm{T}_{\mathrm{g}}$ of RX771/HY1300. The total loss and the temperature variation of these transducers are positive functions of the mechanical loss, related directly with the surface displacement. However, for the two-layer transducer with silver-loaded epoxy, the curves have turning points where the normalized loss constant and temperature are 0.47 and $41.6{ }^{\circ} \mathrm{C}$, respectively. Above these values, the surface displacement (mechanical loss) drops down although the total loss and temperature are still increasing. The temperature has significantly affected the mechanical properties and the resonant frequency of this transducer. When the temperature above $41.6^{\circ} \mathrm{C}$, the transducer started to shift to off-resonance condition and the total loss characteristics started to vary off from resonance condition, which the authors believe this is because the silver-loaded bondline starts to soften though it can still bond the piezoceramics at even higher temperature (Wu \& Cochran, 2010).

\section{Conclusion}

In this chapter, the behaviour of adhesively-bonded multilayer piezoelectric ultrasonic transducers with two typical adhesives has been investigated under self-heating conditions. The material characteristic variation of high Curie temperature lead metaniobate piezoelectric cermaic, used to manufacture the multilayer structures, with different temperature were studied. The temperature rise and mechanical output characteristics of adhesively-bonded multilayer ultrasonic transducers resulted from self-heating under dynamic drive conditions were presented. Investigation has also been carried out into the loss characteristics derived from measured time-temperature behaviour of multilayer piezoelectric ultrasonic transducers with adhesive bondlines. It is concluded that elevated temperature changes the characteristics of the piezoelectric material in the same way, the dramatically different effects of self-heating and the elevated temperature on the 
performances of the multilayer transducers are still presented with the respective effects on the elastic characteristics of each adhesive bondline, and in turn the resonant characteristics of the whole structure to different degrees.

\section{Acknowledgement}

Zhengbin $\mathrm{Wu}$ was sponsored by a University of Paisley (University of the West of Scotland) Studentship and Sandy Cochran was supported by a UK EPSRC Advanced Fellowship during the period of the work described in this chapter. Zhengbin $\mathrm{Wu}$ is also supported by the National Natural Science Foundation of China (NSFC, No. 10804075) and Shenzhen Science and Technology Research and Development Foundation 2008 (Approval no. 343).

\section{References}

Abrar, A. \& Cochran, S. (2007). Mathematical optimization of multilayer piezoelectric devices with nonuniform layers by simulated annealing. IEEE Transactions on Ultrasonics, Ferroelectrics, and Frequency Control, Vol. 54, No. 10, October 2007, pp. 1920-1929, ISSN 0885-3010

Akdogan, E. K.; Allahverdi, M. \& Safari, A. (2005). Piezoelectric composites for sensor and actuator applications. IEEE Transactions on Ultrasonics, Ferroelectrics, and Frequency Control, Vol. 52, No. 5, May 2005, pp. 746-775, ISSN 0885-3010

ANSI/IEEE Std 176-1987 (1987). IEEE Standard on Piezoelectricity, IEEE, New York

Ballato, A. (1995). Piezoelectricity: old effect, new thrusts. IEEE Transactions on Ultrasonics, Ferroelectrics, and Frequency Control, Vol. 42, No. 5, September 1995, pp. 916-926, ISSN 0885-3010

Cochran, A.; Reynolds, P. \& Hayward, G. (1997). Multilayer piezocomposite transducers for applications of low frequency ultrasound, Proceedings of IEEE International Ultrasonics Symposium, pp. 1013-1016, ISBN 0-7803-4153-8, Toronto, Canada, October 1997, IEEE, New York

Cochran, A.; Reynolds, P. \& Hayward, G. (1998). Progress in stacked piezocomposite ultrasonic transducers for low frequency applications. Ultrasonics, Vol. 36, No. 10, October 1998, pp. 969-977, ISSN 0041-624X

Cochran, A. and Hayward, G. (1999). Multilayer piezocomposite ultrasonic transducers operating below $50 \mathrm{kHz}$, Proceedings of IEEE International Ultrasonics Symposium, pp. 953-956, ISSN 1051-0117, Nevada, USA, October 1999, IEEE, New York

Dubus B.; Haw, G.; Granger, C. \& Ledez, O. (2002). Characterization of multilayered piezoelectric ceramics for high power transducers. Ultrasonics, Vol. 40, No. 1-8, May 2002, pp. 903-906, ISSN 0041-624X

Duck, F. A.; Baker, A. C. \& Starritt, H. C. (1998). Ultrasound in Medicine, Institute of Physics Publishing, ISBN 0-75-030593-8, London

Flint, E.; Liang, C. \& Rogers, C. A. (1995). Electromechanical analysis of piezoelectric stack active member power consumption. Journal of Intelligent Material Systems and Structures, Vol. 6, No. 1, January 1995, pp. 117-124, ISSN 1045-389X

Foote, K. G. (2008). Underwater acoustic technology: review of some recent developments, Proceedings of Oceans 2008 Conference, pp. 1327-1332, ISSN 0197-7385, Quebec, Canada, September 2008, IEEE, New York 
Fukada, E. (2000). History and recent progress in piezoelectric polymers. IEEE Transactions on Ultrasonics, Ferroelectrics, and Frequency Control, Vol. 47, No. 6, November 2000, pp. 1277-1290, ISSN 0885-3010

Goldberg, R. L. \& Smith, S. W. (1994). Multilayer piezoelectric ceramics for two-dimensional array transducers. IEEE Transactions on Ultrasonics, Ferroelectrics, and Frequency Control, Vol. 41, No. 5, September 1994, pp. 761-771, ISSN 0885-3010

Greenstein, M. \& Kumar, U. (1996). Multilayer piezoelectric resonators for medical ultrasound transducers. IEEE Transactions on Ultrasonics, Ferroelectrics, and Frequency Control, Vol. 43, No. 4, July 1996, pp. 620-622, ISSN 0885-3010

Hossack, J. A. \& Auld, B. A. (1993). Improving the characteristics of a transducer using multiple piezoelectric layers. IEEE Transactions on Ultrasonics, Ferroelectrics, and Frequency Control, Vol. 40, No. 2, March 1993, pp. 131-139, ISSN 0885-3010

Hoyle, B. S. \& Luke, S. P. (1994). Ultrasound in the process industries. Engineering Science and Education Journal, Vol. 3, No. 3, June 1994, pp. 119-122, ISSN 0963-7346

Jaffe, B.; Cook, W. R. \& Jaffe, H. (1971). Piezoelectric Ceramics, Academic Press Inc., ISBN 012-379550-8, London

Kwok, K. W.; Chan, H. L. W. \& Choy, C. L. (1997). Evaluation of the material parameters of piezoelectric materials by various methods. IEEE Transactions on Ultrasonics, Ferroelectrics, and Frequency Control, Vol. 44, No. 4, July 1997, pp. 733-742, ISSN 0885-3010

Lakin, K. M. (2005). Thin film resonator technology. IEEE Transactions on Ultrasonics, Ferroelectrics, and Frequency Control, Vol. 52, No. 5, May 2005, pp. 707-716, ISSN 0885-3010

Mason, W. P. (1976). Sonics and ultrasonics: early history and applications. IEEE Transactions on Sonics and Ultrasonics, Vol. SU-23, No. 4, July 1976, pp. 224-232, ISSN 0018-9537

Mills, D. M. \& Smith, S. W. (1999). Multi-layered PZT/polymer composites to increase signal-to-noise ratio and resolution for medical ultrasound transducers. IEEE Transactions on Ultrasonics, Ferroelectrics, and Frequency Control, Vol. 46, No. 4, July 1999, pp. 961-971, ISSN 0885-3010

Ochi, A.; Takahashi, S. \& Tagami, S. (1985). Temperature characteristics for multilayer piezoelectric ceramic actuator. Japanese Journal of Applied Physics, Vol. 24, Supplement 24-3, 1985, pp. 209-212, ISSN 0021-4922

Pritchard, J.; Ramesh, R. \& Bowen, C.R. (2004). Time-temperature profiles of multi-layer actuators, Sensors and Actuators A: Physical, Vol. 115, No. 1, September 2004, pp. $140-$ 145, ISSN 0924-4247

Ritter, T.; Geng, X.; Shung, K. K.; Lopath, P. D.; Park, S-E. \& Shrout, T. R. (2000). Single crystal PZN/PT-polymer composites for ultrasound transducer applications. IEEE Transactions on Ultrasonics, Ferroelectrics, and Frequency Control, Vol. 47, No. 4, July 2000, pp. 792-800, ISSN 0885-3010

Robertson, D. \& Cochran, S. (2002). Experimental investigation of alternative pre-stress components for a 3-1 connectivity multilayer piezoelectric-polymer composite ultrasonic transducer. Ultrasonics, Vol. 40, No. 1-8, May 2002, pp. 913-919, ISSN 0041-624X

Sherrit, S.; Wiederick, H. D. \& Mukherjee, B. K. (1992). Non-iterative evaluation of the real and imaginary material constants of piezoelectric resonators. Ferroelectrics, Vol. 134, No. 1-4, September 1992, 134, pp. 111-119, ISSN 0015-0193 
Sherrit, S.; Yang, G.; Wiederick, H. D. \& Mukherjee, B. K. (1999). Temperature dependence of the dielectric, elastic and piezoelectric material constants of lead zirconate titanate ceramics, Proceedings of International Conference on Smart Material, Structures and Systems, pp. 121-126, Bangalore, India, July 1999

Sherrit, S.; Bao, X.; Sigel, D. A.; Gradziel, M. J.; Askins, S. A.; Dolgin, B. P. \& Bar-cohen, Y. (2001). Characterization of transducers and resonators under high drive levels, Proceedings of IEEE International Ultrasonics Symposium, pp. 1097-1100, ISBN 0-78037177-1, Atlanta, USA, October 2001, IEEE, New York

Sittig, E. K. (1967). Transmission parameters of thickness-driven piezoelectric transducers arranged in multilayer configurations, IEEE Transactions on Sonics and Ultrasonics, Vol. SU14, No. 4, October 1967, pp. 167-174, ISSN 0018-9537

Smits, J.G. (1976). Iterative method for accurate determination of the real and imaginary parts of the materials coefficients of piezoelectric ceramics. IEEE Transactions on Sonics and Ultrasonics, Vol. SU-23, No. 6, November 1976, pp. 393-402, ISSN 00189537

Takahashi, M.; Yamauchi, F. \& Takahashi, S. (1974). Stabilization of resonance frequencies in piezoelectric ceramic resonators against sudden temperature change, Proceedings of IEEE Frequency Control Symposium, pp. 109-116, New Jersey, USA, May 1974, IEEE, New York

Thompson, R. B. \& Thompson, D. O. (1985). Ultrasonics in nondestructive evaluation. Proceedings of the IEEE, Vol. 73, No. 12, December 1985, pp. 1716-1755, ISSN 00189219

Uchino, K. \& Hirose, S. (2001). Loss mechanisms in piezoelectrics: how to measure different losses separately. IEEE Transactions on Ultrasonics, Ferroelectrics, and Frequency Control, Vol. 48, No. 1, January 2001, pp. 307-321, ISSN 0885-3010

Wang, X.; Ehlers, C. \& Neitzel, M. (1996). Electro-mechanical dynamic analysis of the piezoelectric stack. Smart Materials and Structures, Vol. 5, No. 4, August 1996, pp. 492-500, ISSN 0964-1726

Wehrsdorfer, E.; Borchhardt, G. \& Karthe, W. (1995). Large signal measurements on piezoelectric stacks. Ferroelectrics, Vol. 174, No. 1, December 1995, pp. 259-275, ISSN 1563-5112

Wu, Z.; Abrar, A.; McRobbie, G.; Gallagher, S. \& Cochran, S. (2003). Implementation of multilayer ultrasonic transducer structures with optimised non-uniform layer thicknesses, Proceedings of IEEE International Ultrasonics Symposium, pp. 1175-1178, ISBN 0-7803-7922-5, Hawaii, USA, October 2003, IEEE, New York

Wu, Z.; Cochran, S.; McRobbie, G. \& Kirk, K. J. (2005). Nondestructive and destructive investigation of bondlines for high-power multilayer ultrasonic transducers for underwater sonar, Proceedings of IEEE International Ultrasonics Symposium, pp. 22192222, ISBN 0-7803-9382-1, Rotterdam, Netherlands, September 2005, IEEE, New York

Wu, Z. \& Cochran, S. (2008). Characterisation of self-heating effects on multilayer ultrasonic transducers with adhesive bondlines. Electronics Letters, Vol. 44, No. 22, October 2008, pp. 1333-1334, ISSN 0013-5194

Wu, Z. \& Cochran, S. (2010). Loss effects on adhesively-bonded multilayer ultrasonic transducers by self-heating. Ultrasonics, Vol. 50, No. 4-5, April 2010, pp. 508-511, ISSN 1874-9968" 
Xia, L. \& Hanagud, S.V. (2004). Extended irreversible thermodynamics modeling for selfheating and dissipation in piezoelectric ceramics. IEEE Transactions on Ultrasonics, Ferroelectrics, and Frequency Control, Vol. 5, No. 12, December 2004, pp. 1582-1592, ISSN 0885-3010

Yao, K.; Uchino, K.; Xu, Y.; Dong, S. \& Lim, L. (2000). Compact piezoelectric stacked actuators for high power applications. IEEE Transactions on Ultrasonics, Ferroelectrics, and Frequency Control, Vol. 47, No. 4, July 2000, pp. 819-825, ISSN 0885-3010

Ye, D. \& Sun, J. Q. (1997). Dynamic analysis of piezoelectric stack actuators including thermal and pyroelectric effects, Proceedings of SPIE International Symposium on Smart Structures and Materials: Mathematics and Control in Smart Structures, pp. 619629, ISBN 0-8194-2452-8, San Diego, USA, March 1997, SPIE, Bellingham

Zheng, J.; Takahashi, S.; Yoshikawa, S.; Uchino, K. \& deVries, J. W. C. (1996). Heat generation in multilayer piezoelectric actuators. Journal of American Ceramic Society, Vol. 79, No. 12, December 1996, pp. 3193-3198, ISSN 0002-7820 


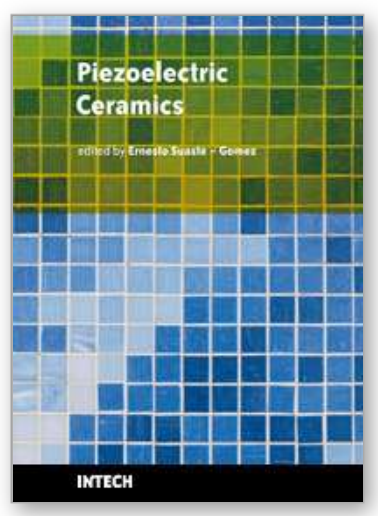

\author{
Piezoelectric Ceramics \\ Edited by Ernesto Suaste-Gomez
}

ISBN 978-953-307-122-0

Hard cover, 294 pages

Publisher Sciyo

Published online 05, October, 2010

Published in print edition October, 2010

This book reviews a big window of opportunity for piezoelectric ceramics, such as new materials, material combinations, structures, damages and porosity effects. In addition, applications of sensors, actuators, transducers for ultrasonic imaging, positioning systems, energy harvesting, biomedical and microelectronic devices are described. The book consists of fourteen chapters. The genetic algorithm is used for identification of RLC parameters in the equivalent electrical circuit of piezoelectric transducers. Concept and development perspectives for piezoelectric energy harvesting are described. The characterization of principal properties and advantages of a novel device called ceramic-controlled piezoelectric with a Pt wire implant is included. Biocompatibility studies between piezoelectric ceramic material and biological cell suspension are exposed. Thus, piezoelectric ceramics have been a very favorable solution as a consequence of its high energy density and the variety of fabrication techniques to obtain bulk or thin films devices. Finally, the readers will perceive a trend analysis and examine recent developments in different fields of applications of piezoelectric ceramics.

\title{
How to reference
}

In order to correctly reference this scholarly work, feel free to copy and paste the following:

Zhengbin Wu, Sandy Cochran and Bo Wu (2010). Investigation of Elevated Temperature Effects on Multiple Layer Piezoelectric Ultrasonic Transducers with Adhesive Bondlines by Self-Heating, Piezoelectric Ceramics, Ernesto Suaste-Gomez (Ed.), ISBN: 978-953-307-122-0, InTech, Available from:

http://www.intechopen.com/books/piezoelectric-ceramics/investigation-of-elevated-temperature-effects-onmultiple-layer-piezoelectric-ultrasonic-transducers

\section{INTECH}

open science | open minds

\section{InTech Europe}

University Campus STeP Ri

Slavka Krautzeka 83/A

51000 Rijeka, Croatia

Phone: +385 (51) 770447

Fax: +385 (51) 686166

www.intechopen.com

\section{InTech China}

Unit 405, Office Block, Hotel Equatorial Shanghai

No.65, Yan An Road (West), Shanghai, 200040, China 中国上海市延安西路65号上海国际贵都大饭店办公楼405单元

Phone: +86-21-62489820

Fax: $+86-21-62489821$ 
(C) 2010 The Author(s). Licensee IntechOpen. This chapter is distributed under the terms of the Creative Commons Attribution-NonCommercialShareAlike-3.0 License, which permits use, distribution and reproduction for non-commercial purposes, provided the original is properly cited and derivative works building on this content are distributed under the same license. 